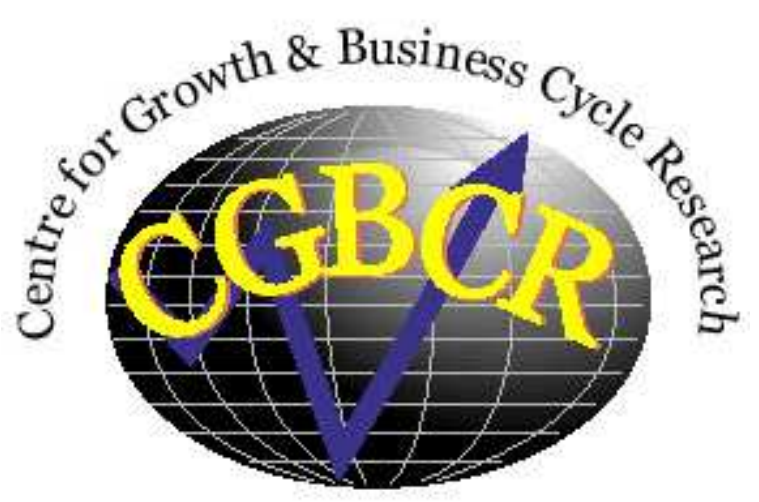

Discussion Paper Series

\title{
Institutions and Financial Dollarization: Indirect Effects based on a Policy Experiment
}

$$
\text { By }
$$

\author{
Kyriakos C. Neanidis and Christos S. Savva
}

Centre for Growth and Business Cycle Research, Economic Studies,

University of Manchester, Manchester, M13 9PL, UK

July 2013

Number 186

Download paper from:

http://www.socialsciences.manchester.ac.uk/cgbcr/discussionpape rs/index.html 


\title{
Institutions and Financial Dollarization: Indirect Effects based on a Policy Experiment
}

\author{
Kyriakos C. Neanidis ${ }^{a}$ and Christos S. Savva ${ }^{b, *}$ \\ ${ }^{a}$ Economics, University of Manchester and Centre for Growth and Business Cycle \\ Research, Manchester, United Kingdom \\ ${ }^{\mathrm{b}}$ Department of Commerce, Finance and Shipping, Cyprus University of Technology, \\ Cyprus
}

\begin{abstract}
We provide evidence that institutional improvements lead to lower levels of financial dollarization through previously unidentified channels. These indirect channels operate in addition to the direct impact identified in the literature and further illustrate the importance of institutions for the extent of banking dollarization. The analysis is based on a unique policy experiment: the admission process of countries to the European Union (EU).
\end{abstract}

Keywords: Dollarization; EU membership; FAVAR; Institutions

JEL Classification: E44; F33; G20

\section{Introduction}

Financial dollarization (FD) has been an increasing phenomenon over the last two decades, particularly amongst developing and emerging economies. The rise in FD has been matched by a growing academic interest with regard to its causal factors. Research in this area has been driven by the role of FD in inducing balance of payments crises, along with financial and liquidity crises in the event of large exchange rate fluctuations, giving rise to sharp contractions in output. The literature has identified a number of determinants of FD, with institutions playing a central role amongst them. In this paper, we contribute to the literature by further stressing the importance of institutions. Compared to the existing literature, however, our study is concerned with the indirect channels via which institutions impact upon FD. Our identification strategy makes use of a historical policy experiment proxying for improvements in a country's institutional framework: the EU accession process.

The roots of FD - defined as the holding by residents of a share of their deposits and loans denominated in foreign currency - are attributed to certain factors for which analytical models have been developed. These include (i) the rates of inflation and exchange rate

\footnotetext{
* Corresponding author. Tel.: +357 25002349; fax: +357 25002674. E-mail address: christos.savva@cut.ac.cy (C.S. Savva).
} 
depreciation in line with the currency substitution theory (Savastano, 1996), (ii) the minimum variance portfolio (mvp) dollarization share according to the optimal portfolio theory (Ize and Levy Yeyati, 2003), (iii) the interest rate differentials between deposits or loans in foreign and local currency (Basso et al., 2007), and (iv) the quality of institutions based on the institutions theory (Levy Yeyati, 2006). With regard to the latter driver, a series of studies has established that institutional progress directly diminishes FD (Honig, 2009; Vieira et al., 2012). ${ }^{1}$ More recently however, and specific to institutional improvements within the EU admission framework, Neanidis (2010) and Kishor and Neanidis (forthcoming) have shown that the EU accession process and entry induces lower deposit dollarization (DD) and higher loan dollarization (LD). These (direct) asymmetric effects of institutional advancement on the two elements of FD are explained, respectively, by the increased confidence instilled upon the private sector in the domestic currency and by the greater convergence of exchange rates to the euro due to eventual adoption of the common currency.

The current paper follows the lead of the latter studies in using the EU accession process as a way of assessing the impact of institutional development on both types of FD. But it differs in an essential way, as the focus is on the indirect effects of institutions on FD via the channels advanced by the theories described above. In other words, in this study we assess the impact of institutions on FD, not directly, but through the other main drivers of FD: inflation, depreciation, mvp dollar share, and interest rate differential. This allows us to examine whether the impact of institutions on FD has been underestimated in earlier studies.

Our analysis, based on data from recent EU members from Central and Eastern Europe, utilizes a factor augmented VAR (FAVAR) estimation technique that takes account of possible endogeneity concerns. The empirical findings indicate significant indirect effects of institutional quality on both DD and LD. Specifically, the long-run impact on FD of its main drivers, as outlined above, is significantly lower in the period for which institutional improvements have been recorded - signified by the accession and entry into the EU. Thus, institutional quality affects FD not only directly, as evidenced in the literature, but also indirectly via the various traditional drivers. This, in turn, implies the multifaceted impact of institutions on FD, which should not be ignored when assessing its total effect. The rest of the paper is outlined as follows. Section 2 describes the data and the model, Section 3 presents the results, and Section 4 briefly offers our conclusions.

\section{Data and model}

We use monthly data on twenty-two series related to FD for ten recent EU members (Bulgaria, the Czech Republic, Estonia, Hungary, Latvia, Lithuania, Poland, the Slovak Republic, Slovenia, and Romania). ${ }^{2}$ The series cover the domestic and foreign real economies, prices, exchange rates, interest rates, and banking sector variables. The data span varies for each country and is determined by the availability of data on FD. Table 1 presents summary statistics for DD and LD, illustrating the variety in their levels and in their volatility across countries. All data are transformed to become stationary via an appropriate transformation such as first differences of levels or of logarithms. ${ }^{3}$ Then, the stationary data are standardized prior to the analysis and used in the estimation of the FAVAR model.

\footnotetext{
${ }^{1}$ For an explanation of the underlying mechanisms, see Levy Yeyati (2006).

${ }^{2}$ We exclude Cyprus and Malta from the 2004 EU enlargement due to their high levels of institutional quality even before EU entry.

${ }^{3}$ The full list of variables, with definitions and transformation codes can be found in the Appendix.
} 
In this setting, let $X_{t}$ denote a $N \times 1$ information matrix that contains the time series of the dataset; $Y_{t}$ a $M \times 1$ vector of endogenous variables that constitutes a subset of $X_{t}$. In the case of the DD regression, $Y_{t}$ contains the degree of DD, the rate of inflation, the rate of domestic currency depreciation, the mvp dollar share, and the interest rate differential. For the case of LD, $Y_{t}$ replaces DD with LD and adds the domestic financial system's net foreign assets (nfa) as a way of controlling for bank's preferences in matching the overall level of assets and liabilities by currency (Neanidis and Savva, 2009). The traditional way of assessing the links among the endogenous variables in $Y_{t}$ is to employ a VAR type specification. Nevertheless, in many applications, additional information (not fully captured by $Y_{t}$ ) may be relevant to modeling the dynamics of these series. As shown by Stock and Watson (2005), the additional information can be captured by a few number of unobserved factors $F_{t}$, (a $K \times 1$ vector) that summarize most of the information contained in $X_{t}{ }^{4}$ This includes country-specific variables that have been found in the literature to significantly influence FD, such as international financial integration and exchange rate policy intervention, but also variables of large economic entities that can spillover across countries, like the US and the euro area economic growth rates and business cycles. These variables are listed in the Appendix as "exogenous variables" and are included in vector $F_{t}$.

The joint dynamics of $\left(F_{t}^{\prime}, Y_{t}^{\prime}\right)$ and the static representation of a dynamic factor model $\left(X_{t}, F_{t}, Y_{t}\right)$ are given by the following equations:

$$
\begin{aligned}
& {\left[\begin{array}{l}
F_{t} \\
Y_{t}
\end{array}\right]=\Phi(L)\left[\begin{array}{l}
F_{t-1} \\
Y_{t-1}
\end{array}\right]+v_{t}} \\
& X_{t}=\Lambda^{f} F_{t}+\Lambda^{y} Y_{t}+v_{t}
\end{aligned}
$$

where $\Phi(L)$ is a conformable lag polynomial of finite order $d$, which may contain a priori restrictions as in the structural VAR literature. ${ }^{5}$ The error term $v_{t}$ is mean zero with covariance matrix $\Sigma$. $\Lambda^{f}$ is a $N \times K$ matrix of factor loadings, while $\Lambda^{y}$ is a $N \times M$ matrix of factor loadings which reflect the degree by which variation in the variables included in vector $X_{t}$ can be explained by each of the factors. Finally, $v_{t}$ is a vector of error terms which are zero mean. ${ }^{6}$

Having estimated the factors $F_{t}$, it is possible to estimate the dynamic FAVAR model in equation (1) by replacing the true factors $F_{t}$ with their estimated counterparts, $\hat{F}_{t}$. This is achieved by using an identifying assumption for the imposed shock. ${ }^{7}$ Following Bernanke et.

\footnotetext{
${ }^{4}$ The main advantage of a FAVAR, compared to a VAR, model is that it represents a more general framework where the importance of unobserved factors can be examined through formal tests. Put differently, the VAR specification is a special case of a FAVAR model. For further details, see Bernanke et al. (2005) and Stock and Watson (2005).

${ }^{5}$ These restrictions include a Cholesky factorization, partial identification via block lower-triangular exclusion, general restrictions, long run restrictions, etc (see for details Stock and Watson, 2005). The lag order used is determined by the Schwartz Information Criterion.

${ }^{6}$ Essentially, the static representation of the dynamic factor model described by equation (2) allows factors to be estimated by principal components. This method allows for some cross-correlation in $v_{\mathrm{t}}$ that must vanish as $N$ goes to infinity (see Stock and Watson, 2002, 2005).

${ }^{7}$ The appropriate number of factors for each case is chosen by the Bai and $\mathrm{Ng}$ (2002) criterion.
} 
al. (2005), we assume a Cholesky identification scheme with the order of variables being \{inflation, depreciation, mvp dollar share, interest rate differential, and DD $\}$ for the DD equation. When estimating the LD equation, the order of the variables is \{net foreign assets, inflation, depreciation, mvp dollar share, interest rate differential, and LD $\}$. The theoretical rationale on how our variables interact through time is not well established, thus we alter the ordering of variables to verify the robustness of results. As discussed further below, we find results to be unchanged.

To assess the impact of institutional progress on FD we split our sample into two periods, the pre-EU and the post-EU. The former period is defined as the period prior to the completion of the negotiation process, which signifies that a negotiating country will soon be joining the EU. The post-EU period corresponds to the period after the completion of this negotiation process. For most countries in our sample this date is December 2002, while for Bulgaria and Romania it is April 2005. As shown by Neanidis (2010) and Kishor and Neanidis (forthcoming), the post-EU period has been associated with significant improvements in the candidate countries' institutional environment as part of the EU accession process. For this reason, our model is estimated separately for the two sub-periods to examine the indirect effects of institutions on FD via the main drivers referred to above.

Our approach has two main advantages compared to the existing literature, which relies on panel data econometric techniques to isolate the effect of the variable(s) of interest. Firstly, it accounts for possible endogeneity by treating all the main drivers of FD as endogenous. Secondly, we do not have to control for every exogenous determinant separately as these are controlled for with the unobservable latent factors. Thus, as long as our parametric structure is correct, our approach yields significant efficiency gains.

\section{Results}

Given our goal to examine the presence of indirect effects of institutional improvements on FD, we focus our attention on the impulse responses of DD and LD to innovations to the other endogenous variables of our FAVAR, before and after the completion of the EU negotiations that ratify a candidate nation's EU admission. These impulse responses are presented in Figures 1 and 2 and illustrate for each country, across the two sub-periods, the effect on DD and LD of a $1 \%$ exogenous shock to each of the main drivers tracked for 48 months. For example, with regard to inflation, we match the process of a $1 \%$ exogenous increase in inflation to the levels of foreign deposits and liabilities in the banking sector. Importantly, this effect is considered separately between the two sub-periods as a way of establishing any differences attributed to improved institutional quality.

Starting with DD, Figure 1 shows that the impulse response functions are in line with the direction of the effects established in the literature. Specifically, in all countries, an exogenous shock to inflation, depreciation, and mvp dollar share contribute positively to DD, while an interest rate differential shock contributes negatively to DD. The explanations for these effects are as follows. Higher rates of inflation and currency depreciation diminish the value of the domestic currency, inducing depositors to switch to foreign currency holdings. A higher mvp dollar share, capturing the relative importance of the volatility of inflation versus that of real depreciation, also leads to foreign currency holdings as a way of avoiding domestic currency risk. Finally, a higher rate of interest on domestic currency deposits compared to foreign currency deposits increases the attractiveness of the former, thus, leading to lower DD. 
The impulse response functions just described apply equally well to both the periods before (in blue color) and after (in red color) the completion of the EU negotiations. In other words, the direction of the exogenous shocks associated with the endogenous variables on DD is not affected by the EU accession procedure. The magnitude of the effect, however, does change between the two periods. In particular, in the post-EU period the impact of the exogenous shocks to the endogenous variables is smaller, compared to the impact of the same shock in the pre-EU period. The smaller size of the effects in the post-EU period reflects the influence of institutional progress and highlights the indirect impact of institutions on DD. This indirect impact is not restricted to some of the endogenous variables, but takes shape without discrimination through all of them, further supporting the multidimensional effect of institutions on DD.

In Figure 2, we observe that the impulse response functions support the general findings in the literature with respect to LD as well. As for the case for DD, exogenous innovations to inflation, depreciation, and mvp dollar share positively contribute to LD, as now also are innovations to interest rate differentials. Innovations to bank's net foreign assets, on the other hand, negatively contribute to LD. The positive contribution of interest rate differentials arises from the fact that a higher rate of interest on local currency loans, leads borrowers to prefer foreign currency loans due to lower cost of borrowing. As for net foreign assets, a higher value reduces LD because banks substitute foreign currency loans to domestic borrowers with foreign assets as a way of matching their assets and liabilities by currency. With regard to potential differences of the size of the effects on LD between the pre- and post-EU periods, the analysis shows once again a more muted response of LD to the exogenous shocks arising from the endogenous variables in the latter period. The effects, however, are not as strong as in the case of DD as there are a few cases for which the effects are either the same between the two periods (for inflation in Poland and the Slovak Rep., for depreciation in Hungary, and for nfa in Estonia and Slovenia), or the effect in the post-EU period exceeds that of the pre-EU period (for mvp dollar share in Poland and the Slovak Rep., for interest rate differential in Estonia and Lithuania, and for nfa in Lithuania). Except for these cases, however, the general finding is that of smaller effects on LD in the post-EU period, indicative of improvements in the institutional environment. ${ }^{8}$

The robustness of our results is verified by changing the order of the endogenous variables in the vector $Y_{t}$ given that our identification lacks solid theoretical argumentation. We run the estimations using all possible orders. Even with a complete reversal of the identification strategy, the impulse response functions convey the same information as those reported in Figures 1 and 2. This means that our results are not driven by the adopted identification strategy.

\section{Conclusion}

This study examines the indirect impact of improvements in the institutional environment on the degree of financial dollarization for ten recent EU member states using a FAVAR model. Innovations lie in dividing the sample period in line with the dates of EU

\footnotetext{
${ }^{8}$ In all cases, we assess the contribution of the unobserved factors $F_{t}$ in the estimation procedure with a joint $F$ test of their significance in explaining an exogenous variation in FD. The results of the tests, available upon request, suggest that the "exogenous variables" used are indeed jointly significant. This confirms our choice of a FAVAR model over a VAR model.
} 
accession and in focusing on previously unidentified channels to capture the indirect effects in this relationship. Once we control for the policy experiment, we find evidence that institutional progress reduces financial dollarization in the post-EU accession period via these indirect channels, which operate complementary to the direct effects identified in the literature. Our findings highlight the multidimensional role of institutions and corroborate the importance of controlling for their indirect effects as a way of avoiding an underestimation of their impact.

\section{References}

Bai, J., and Ng, S., 2002. Determining the number of factors in approximate factor models. Econometrica 70 (1), 191-221.

Barajas, A., Morales, R.A., 2003. Dollarization of liabilities: beyond the usual suspects', IMF Working Paper No. 03/11.

Basso, H.S., Calvo-Gonzalez, O., Jurgilas, M., 2007. Financial dollarization: The role of banks and interest rates. ECB Working Paper 748.

Beck, T., Demirgüç-Kunt, A., 2009. Financial institutions and markets across countries and over time: data and analysis. World Bank Policy Research Working Paper No. 4943.

Bernanke, B., Boivin, J., Eliasz, P.S., 2005. Measuring the effects of monetary policy: A factor-augmented vector autoregressive (FAVAR) approach. Quarterly Journal of Economics 120 (1), 387-422.

Honig, A., 2009. Dollarization, exchange rate regimes and government quality. Journal of International Money and Finance 28(2), 198-214.

Ize, A., Levy-Yeyati, E., 2003. Financial dollarization. Journal of International Economics $59,323-347$.

Kishor, N.K., Neanidis, K.C., forthcoming. What is driving financial dollarization in transition economies? A dynamic factor analysis. Macroeconomic Dynamics.

Lane, P. R., Milesi-Ferretti, G.M., 2007. The external wealth of nations mark II: Revised and extended estimates of foreign assets and liabilities, 1970-2004. Journal of International Economics 73(2), 223-50.

Levy Yeyati, E., 2006. Financial dollarization: Evaluating the consequences. Economic Policy, 61-118.

Neanidis, K.C., 2010. Financial dollarization and European Union membership. International Finance 13(2), 257-282.

Neanidis, K.C, Savva, C.S., 2009. Financial dollarization: Short-run determinants in transition economies. Journal of Banking and Finance 33, 1860-1873.

Savastano, M. 1996. Dollarization in Latin America: recent evidence and some policy issues', IMF Working Paper No. 96/4.

Stock, J.H., Watson, M.W., 2002. Macroeconomic Forecasting Using Diffusion Indexes. Journal of Business and Economic Statistics 20 (2), 147-162.

Stock, J.H., Watson, M.W., 2005. Implications of Dynamic Factor Models for VAR Analysis. NBER Working Paper No. 11467.

Uhlig, H., 2005. What are the effects of monetary policy on output? Results from an agnostic identification procedure. Journal of Monetary Economics 52(2), 381-419.

Vieira, F.A.C., M. Holland, and M.F. Resende, 2012. Financial dollarization and systemic risks: New empirical evidence. Journal of International Money and Finance 31, 16951714. 
Appendix. Variable definition and sources

Variable

Definition [source]

Transformation

code

Endogenous variables

Foreign currency denominated deposits to total deposits of residents

Deposit dollarization held in resident banks [IMF, International Financial Statistics (IFS)

and National Central Banks (NCB)]

Loan dollarization

Foreign currency denominated credit to total credits of residents

issued by resident banks [IFS and NCB]

Inflation rate

Logarithmic difference of the consumer price index [IFS]

Depreciation rate

Logarithmic difference of nominal official exchange rate (national currency/USD) [IFS]

$[\operatorname{Var}($ Inflation $)+\operatorname{Cov}($ Inflation, $\Delta($ Real exchange rate $))] /[$

$\operatorname{Var}($ Inflation $)+\operatorname{Var}(\Delta($ Real exchange rate $))+2 \operatorname{Cov}($ Inflation, $\Delta$ (Real

MVP dollar share exchange rate))]. Following Neanidis (2010), we compute MVP based on all historical information up to the observation point [Author's calculation]

Interest rate differential

Deposit and loan interest rate differences (local currency - foreign currency)/100 [IFS and NCB]

Net foreign assets

The ratio of commercial banks' and other depository corporation's foreign assets minus external liabilities to total domestic deposits [IFS and NCB]

Exogenous variables

Financial development

(Private credit by deposit money banks and other financial institutions)/GDP [Beck and Demirgüç-Kunt (2009)]

International financial integration

Volume-based measure of international financial integration: (total external assets + total external liabilities)/GDP [Lane and MilesiFerretti (2007)]

Trade openness

The ratio of trade to GDP [WDI]

Indicator of exchange rate intervention as constructed by Barajas

Intervention and Morales (2003) [Author's calculation drawn from IFS]

Index of asymmetry of exchange rate movements as constructed by

Asymmetry

Rennhack and Nozaki (2006) [Author's calculation]

Corruption

Inverse of corruption perception index [Transparency International]

Economic growth rate

Logarithmic difference of industrial production index [IFS]

Economic growth rate

of the USA

Logarithmic difference of the US industrial production index [IFS]

Economic growth rate

of the Euro area

Logarithmic difference of the Euro area industrial production index [IFS]

Fluctuating levels of economic activity estimated using an HP filter

Business cycle

Business cycle of the

USA

[Author's calculation]

Fluctuating levels of economic activity in the USA

Business cycle of the

Euro area

Fluctuating levels of economic activity in the Euro area

USA inflation rate

Logarithmic difference of the US consumer price index [IFS]

Euro area inflation rate

MVP dollar share of the

Euro area

Logarithmic difference of the Euro area consumer price index [IFS]

Same definition as above but for Euro area [Author's calculation]

Notes: Transformation codes are 1 - no transformation, 2 - first difference, 3 - first difference of logarithm. 
Table 1. Summary Statistics of Deposit and Loan Dollarization

\begin{tabular}{|c|c|c|c|c|c|c|c|c|c|c|}
\hline & & Deposi & ollarizatio & & & & Loan & llarizatio & & \\
\hline Country & Period & Mean & Std Dev & Min & Max & Period & Mean & Std Dev & Min & Max \\
\hline Czech Rep. & 1993:1-2009:11 & 11.10 & 2.10 & 7.14 & 15.51 & 1993:1-2009:11 & 11.82 & 4.84 & 2.56 & 22.69 \\
\hline Estonia & 1993:1-2009:11 & 27.08 & 8.71 & 4.39 & 41.23 & 1993:1-2009:11 & 64.82 & 26.76 & 4.60 & 87.10 \\
\hline Latvia & 1993:1-2009:11 & 46.01 & 6.23 & 30.00 & 60.00 & 1994:1-2009:11 & 64.04 & 12.22 & 49.50 & 93.48 \\
\hline Lithuania & 1993:12-2009:12 & 35.68 & 8.05 & 21.90 & 49.03 & 1993:12-2009:12 & 52.97 & 11.45 & 32.71 & 73.46 \\
\hline Poland & 1993:1-2009:11 & 19.54 & 6.56 & 9.93 & 35.82 & 1996:12-2009:11 & 24.18 & 5.32 & 12.14 & 36.68 \\
\hline Romania & 1993:9-2009:11 & 36.42 & 6.41 & 25.00 & 52.73 & 1993:12-2009:11 & 51.07 & 12.79 & 17.17 & 64.77 \\
\hline
\end{tabular}

Sources: IMF, International Financial Statistics and National Central Banks. The end of the coverage period is shorter for the Slovak Republic and Slovenia as both have adopted the Euro as their legal tender in January 2009 and January 2007, respectively. 
Figure 1. Impulse Response Functions on Deposit Dollarization

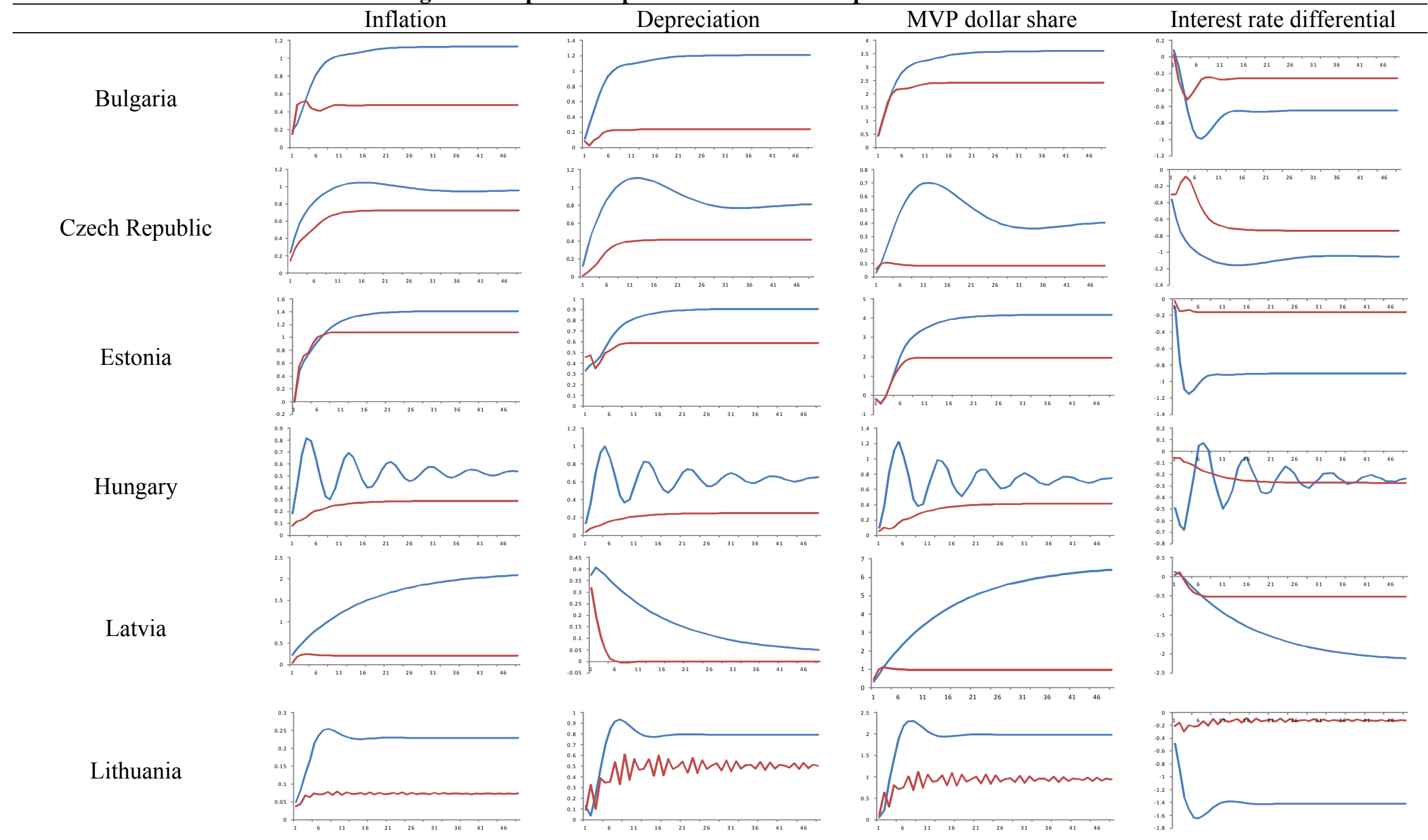


Poland
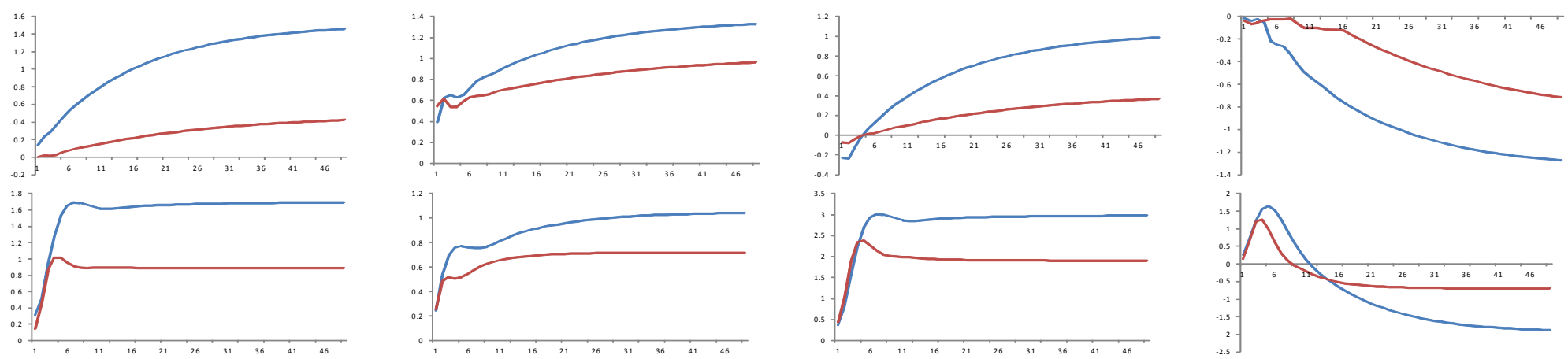

\section{Romania}
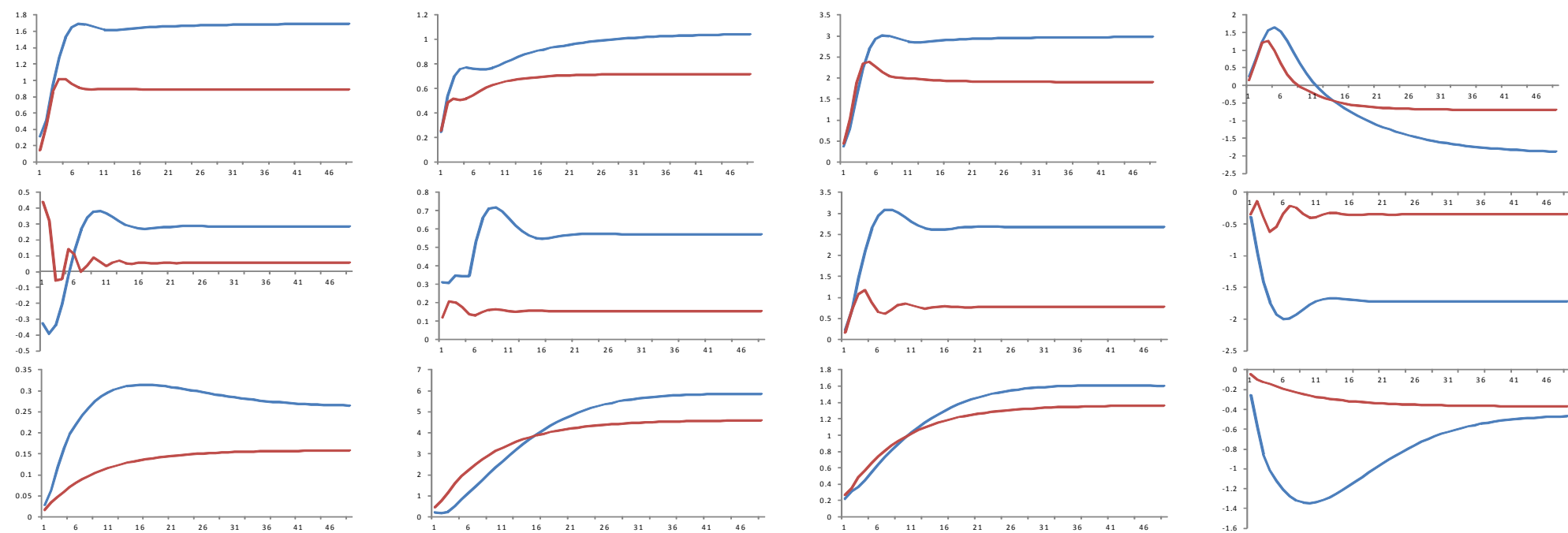

Slovak Republic

Slovenia
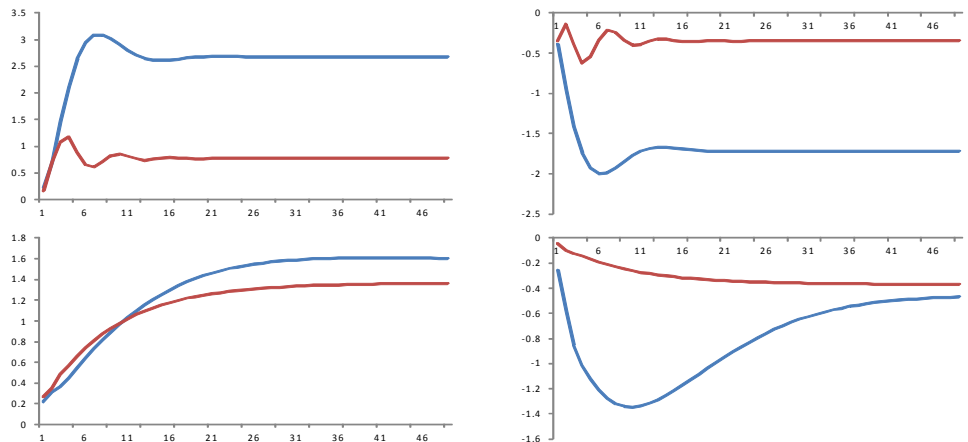

Notes: This figure tracks the impact of a $1 \%$ shock on inflation, depreciation, MVP and interest rate differential on the deposit dollarization of the domestic economy for a period of 48 months. The blue line denotes the impact during the pre-EU period, while the red line during the post-EU period. 
Figure 2. Impulse Response Functions on Loan Dollarization

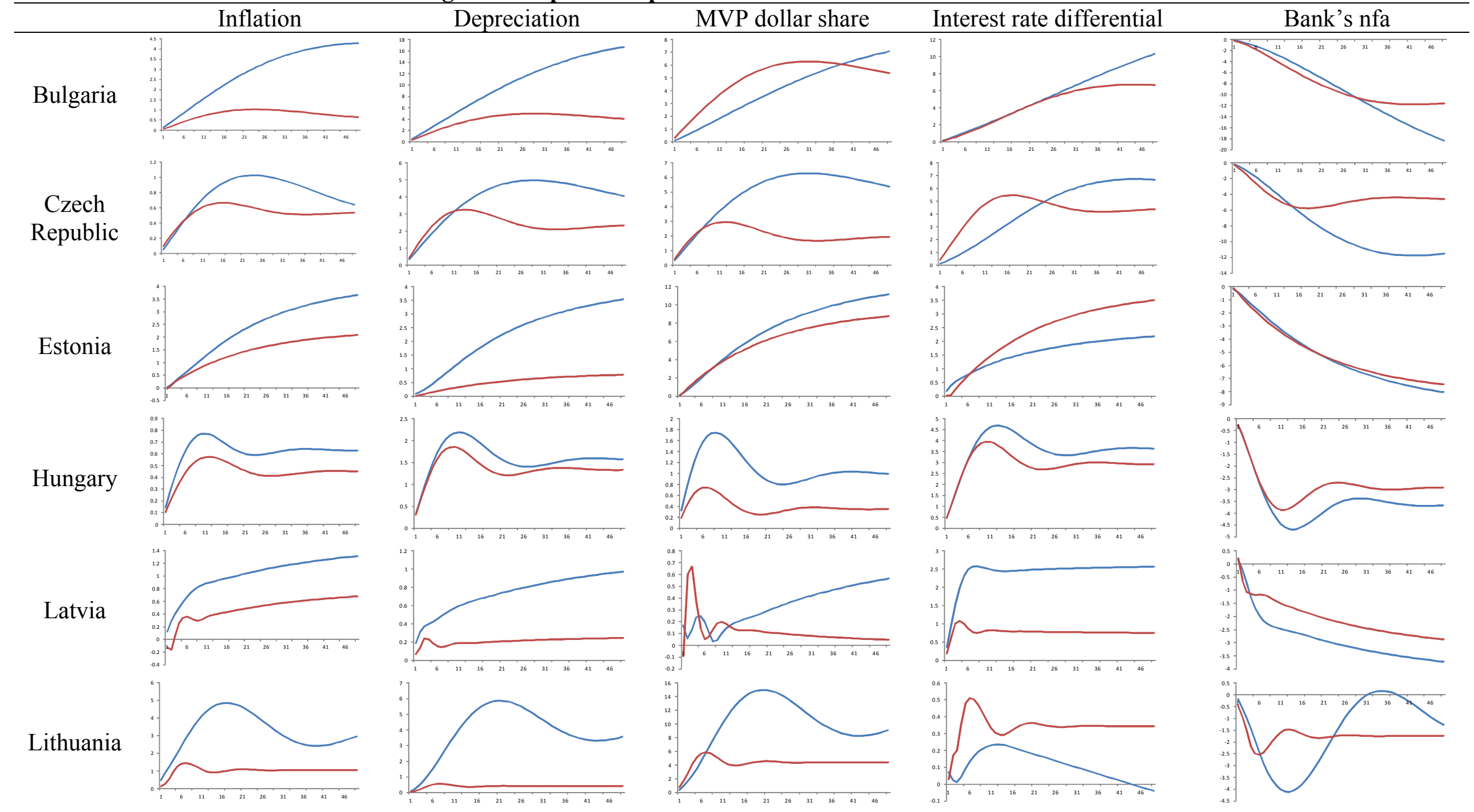




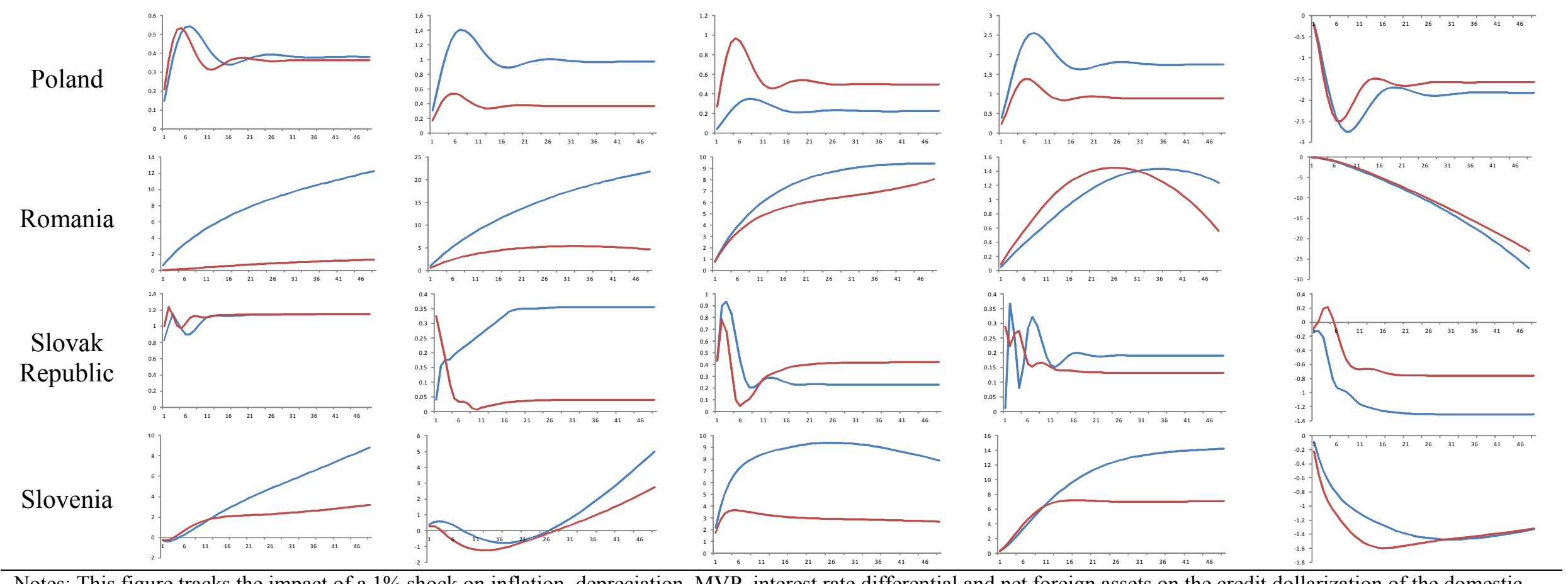

Notes: This figure tracks the impact of a $1 \%$ shock on inflation, depreciation, MVP, interest rate differential and net foreign assets on the credit dollarization of the domestic economy for a period of 48 months. The blue line denotes the impact during the pre-EU period, while the red line during the post-EU period. 